\title{
Peroxisome proliferator-activated receptor- $\gamma$ is downregulated in ulcerative colitis and is involved in experimental colitis-associated neoplasia
}

\author{
XIAOTAN DOU $^{1}$, JUNHUA XIAO ${ }^{2}$, ZILIANG JIN $^{3}$ and PING ZHENG ${ }^{2}$ \\ ${ }^{1}$ Department of Gastroenterology, Nanjing Drum Tower Hospital, Nanjing University, Nanjing, Jiangsu 210000; \\ ${ }^{2}$ Department of Gastroenterology, Shanghai East Hospital, Tongji University, Shanghai 200085; \\ ${ }^{3}$ Department of Oncology, Shanghai First People's Hospital, Shanghai Jiaotong University, Shanghai 200085, P.R. China
}

Received May 29, 2014; Accepted March 12, 2015

DOI: $10.3892 / 01.2015 .3397$

\begin{abstract}
The aim of the present study was to evaluate the expression of peroxisome proliferator-activated receptor (PPAR) $-\gamma$ in inflammatory bowel disease (IBD), and to also identify the association between PPAR- $\gamma$ and the clinical features of patients with IBD. An azoxymethane $(\mathrm{AOM}) /$ dextran sodium sulfate (DSS) animal model of colitis-associated neoplasia was established to investigate the protective effect of 5-aminosalicylic acid (5-ASA) and to explore the changes in the expression of PPAR- $\gamma$ during this process. A total of 66 specimens of colorectal tissue obtained from biopsy performed on IBD patients and 30 healthy control individuals were immunohistochemically stained for PPAR- $\gamma$. An AOM/DSS animal model of colitis-associated neoplasia was then established. Reverse transcription quantitative polymerase chain reaction was conducted and it was found that, compared with the control group and patients with Crohn's disease $(\mathrm{CD})$, the expression of PPAR- $\gamma$ in the intestinal tissue of patients with ulcerative colitis (UC) was significantly decreased $(\mathrm{P}=0.027$ and 0.046 , respectively). The expression of PPAR- $\gamma$ was found to be negatively associated with the disease activity of UC and was not associated with the severity of disease, site of lesions or CD characteristics. Administration of 5-ASA decreased the colitis and tumor burden of colons. The expression level of PPAR- $\gamma$ in the intestinal tissue was also increased in the AOM/DSS/5-ASA group compared with AOM/DSS group $(\mathrm{P}<0.001)$. PPAR $-\gamma$ is an important factor in the pathogenesis of UC and colitis-associated cancer. The present study found that 5-ASA significantly alleviates the colitis and tumor burden in a mouse model of
\end{abstract}

Correspondence to: Dr Ping Zheng, Department of Gastroenterology, Shanghai East Hospital, Tongji University, 150 Jimo Road, Shanghai 200085, P.R. China

E-mail: doctorzhengping@163.com

Key words: peroxisome proliferator-activated receptor- $\gamma$, ulcerative colitis, colonic neoplasms, 5-aminosalicylic acid
AOM/DSS-induced colitis-associated neoplasia, and promotes the expression of PPAR- $\gamma$ in the intestinal tract.

\section{Introduction}

Ulcerative colitis (UC) is a non-specific intestinal inflammatory disease and the pathogenesis of the disease has not been fully elucidated at present. Previous studies have revealed that individuals suffering from UC are at an increased risk of developing colitis-associated cancer (CAC), which accounts for $15 \%$ of inflammatory bowel disease (IBD)-associated mortalities (1). Meanwhile, patients with Crohn's disease (CD), a subtype of IBD, have a lower risk for colorectal cancer compared with UC patients, and the pathogenesis is largely unknown. The main strategy for CAC prevention in patients with chronic UC is currently based on the identification of neoplasia by surveillance colonoscopy. However, there is considerable interest in the possibility of primary chemoprevention (2).

Peroxisome proliferator-activated receptors (PPARs) are ligand-activated transcription factors that belong to a superfamily of nuclear hormone receptors and comprise a subfamily with three different isoforms, PPAR- $\alpha$, PPAR $-\gamma$ and PPAR- $\beta / \delta$. Previous studies (3-5) have reported that PPAR- $\gamma$ plays an important role in maintaining the intestinal immune balance, and may exert anti-inflammatory and antineoplastic effects.

A standard drug used for the maintenance of the remission of UC is 5-aminosalicylic acid (5-ASA). Epidemiological data has suggested that 5-ASA prevents colorectal cancer in patients receiving the drug (6), although the mechanism of action has yet to be fully elucidated. As 5-ASA is a ligand for PPAR- $\gamma$ (7), the dependence of the anti-proliferative effects of 5-ASA on PPAR- $\gamma$ has been investigated, but the results have been inconsistent. Schwab et al (5) revealed that 5-ASA arrested the cell cycle of Caco2, HT29 and HCT116 cells in the $G_{0} / G_{1}$ phase and induced apoptosis in a manner that partly depended on PPAR- $\gamma$. However, Koelink et al (8) found that GW9662 (a selective PPAR- $\gamma$ antagonist) was not able to block the anti-proliferative effects of 5-ASA, while the agent was able to block the anti-proliferative effect of troglitazone. Kohno et al (9) reported that the administration of the PPAR 
ligand troglitazone significantly inhibited the incidence and multiplicity of the colonic adenocarcinoma induced by azoxymethane (AOM)/dextran sodium sulfate (DSS) in mice. The administration of troglitazone also decreased the proliferating cell nuclear antigen (PCNA)-labeling index and the expression of $\beta$-catenin, $\mathrm{COX}-2$, inducible nitric oxide synthase (iNOS) and nitrotyrosine (9). The treatments increased the apoptosis index in the colonic adenocarcinoma tissues. Clearly, systematic studies are required to confirm the role of PPAR- $\gamma$ in IBD and to confirm the anti-proliferative effects mediated by 5-ASA.

To understand the pathogenesis of IBD and CAC, several animal models have been established. One widely used and thoroughly described CAC model is the AOM/DSS model. In this model, AOM is administered to promote tumor formation and DSS dissolved in the drinking water of rodents induces intestinal inflammation, as well as crypt damage and crypt loss. When DSS is administered for a number of days, followed by a period of normal drinking water, the inflammatory period is followed by a period of healing and repair that resembles the exacerbation and remission stages in human UC $(10,11)$. DSS-induced colitis in the AOM mouse model has been demonstrated to accelerate the development of colorectal tumors without altering the pathological characteristics of the tumors and to be useful as a colitis-associated intestinal cancer model $(12,13)$.

The present study aimed to evaluate the PPAR- $\gamma$ levels in IBD and the association between PPAR- $\gamma$ and the clinical features of patients with IBD. In addition, an AOM/DSS mouse model of colitis-associated neoplasia was established to investigate the protective effect of 5-ASA and to explore the changes in the expression of PPAR- $\gamma$ during this process.

\section{Materials and methods}

Sample collection. In total, 66 IBD biopsy samples, consisting of $38 \mathrm{UC}$ and 28 Crohn's disease (CD) tissue samples, and 30 healthy colorectal mucosa specimens were obtained from the Endoscopy Center of Shanghai First People's Hospital (Shanghai, China). The tissue specimens were collected between March 2010 and March 2011. The UC patients consisted of 20 males and 18 females, with ages that ranged between 17 and 62 years and a median age of 39 years. The CD patients consisted of 18 males and 10 females, with ages that ranged between 16 and 59 years and a median age of 36.9 years. Out of the patients with $\mathrm{UC}$ and CD, $25 \mathrm{UD}$ and $20 \mathrm{CD}$ patients were in an active stage of disease. Of the 30 healthy controls, consisting of 11 males and 19 females, the ages ranged between 25 and 57 years, with a median age of 43 years. Ethical approval was obtained from the Research Ethics Committee of the First People's Hospital of Shanghai Jiaotong University. All tissue samples were anonymized according to ethical and legal standards [Standard for quality management of clinical research (SFDA-GCP), 2003; http://www.sda.gov.cn/WS01/ CL0053/24473.html] and informed consent was obtained from each patient or their family.

Animals and treatment. In total, 36 female BALB/c mice were obtained from the Shanghai Experimental Animal Facility of the Chinese Academy of Sciences (Shanghai, China). The mice were purchased at six weeks of age. The mice were housed in an environment with controlled temperature $\left(20-25^{\circ} \mathrm{C}\right)$, humidity (40-70\%) and day-night cycles (12 h of light and $12 \mathrm{~h}$ of darkness), with free access to standard laboratory feed and water. The investigations were performed in accordance with the guidelines set by the Ministry of Health of the People's Republic of China regarding the care and use of animals for experimental procedures (http://www.gov.cn/gongbao/ content/2011/content_1860757.htm). The AOM/DSS model of colitis-associated colorectal carcinogenesis was employed in the present study according to the experimental treatment protocol outlined in Fig. 1. Following an acclimation period, the mice were randomly and equally divided into three groups, with 12 mice per group. For the model group, $10 \mathrm{mg} / \mathrm{kg}$ AOM (Sigma-Aldrich, St. Louis, MO, USA) was administered to the mice through an injection when they reached seven weeks of age. Treatment with DSS (molecular mass, 30-50 kDa; MP Biomedicals LLC, Santa Ana, CA, USA) began three days subsequent to the administration of 5-ASA and continued for three cycles, with each cycle consisting of treatment with drinking solution containing 4\% DSS for seven days, followed by 14 days of untreated water. The treatment group received 150 mg/kg 5-ASA (Tokyo Chemical Industry, Co., Ltd, Tokyo, Japan) through a diet containing $0.15 \%$ 5-ASA, which was manufactured by the Shanghai Experiment Animal Facility of Chinese Academy of Sciences and stored in light-free conditions. The 5-ASA dose was calculated based on the estimation that a mouse weighing $20 \mathrm{~g}$ consumes a daily diet of $5 \mathrm{~g}$, consuming $2 \mathrm{~g}$ and wasting $3 \mathrm{~g}$ per day. The remaining group acted as a control and received untreated drinking water at all times.

Assessment of inflammation. At the end of first week, the clinical disease activity index (DAI) was measured using the previously described protocol (14). The DAI ranged between 0 and 4 and was calculated from the sum of scores provided for percentage loss of body weight, stool consistency and presence or absence of fecal blood. Body weight loss was scored as follows: 0, none; $1,1-5 \% ; 2,5-10 \% ; 3,10-20 \%$; and $4,>20 \%$. Stool consistency was scored as: 0, well-formed pellets; 2, loose stools; and 4, diarrhea. The presence or absence of fecal blood was scored as: 0 , negative hemoccult test; 2 , positive hemoccult test; and 4, gross bleeding. Three mice in each group were randomly selected and sacrificed at the end of the first week for the analysis of colonic inflammation and ulceration. Hematoxylin and eosin (HE) staining was performed using a previously described protocol (15) to assess the inflammation and integrity of the intestinal mucosa.

General observation and gross anatomy. The body weight of the mice was recorded at the time of AOM injection, and at the beginning and end of each cycle of DSS administration. During the period of DSS consumption and for the first week of untreated water consumption, data regarding the mental state, gloss of body hair, appearance of perianal region, presence of thin or blood-containing stool, and mortality of the mice were also recorded. Particular attention was paid to the perianal tumor at day 42 , during the third cycle of DSS. The remaining animals were sacrificed subsequent to three cycles of treatment. The entire colon and rectum 
Table I. Expression of PPAR- $\gamma$ in patients with inflammatory bowel disease $(n=96)$.

\begin{tabular}{|c|c|c|c|c|c|c|}
\hline \multirow[b]{2}{*}{ Group } & \multirow[b]{2}{*}{$\mathrm{n}$} & \multicolumn{4}{|c|}{ PPAR- $\gamma$ expression } & \multirow[b]{2}{*}{ Positive rate, $\mathrm{n}(\%)$} \\
\hline & & - & + & ++ & +++ & \\
\hline $\mathrm{CD}$ & 28 & 11 & 6 & 9 & 2 & $17(60.71)^{\mathrm{a}}$ \\
\hline $\mathrm{UC}$ & 38 & 25 & 7 & 4 & 2 & $13(34.21)$ \\
\hline Control & 30 & 11 & 3 & 13 & 3 & $19(63.33)^{\mathrm{a}}$ \\
\hline
\end{tabular}

${ }^{\mathrm{a}} \mathrm{P}<0.05$ vs. UC group. PPAR- $\gamma$, peroxisome proliferator-activated receptor- $\gamma ; \mathrm{CD}$, Crohn's disease; UC, ulcerative colitis; -, absent; +, weak; ++ , moderate; +++ , strong.

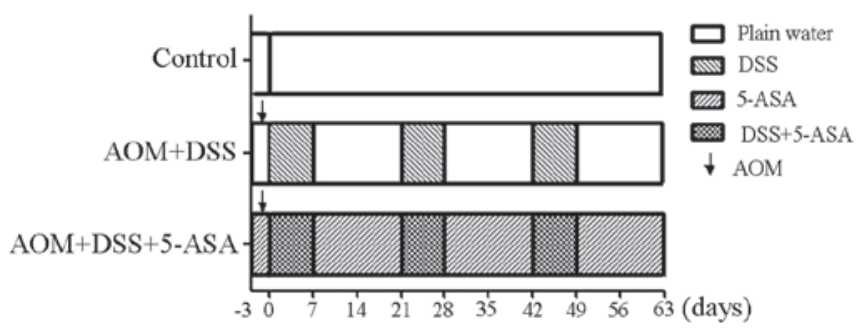

Figure 1. Protocol for the animal model. The arrows indicate the administration of $10 \mathrm{mg} / \mathrm{kg}$ AOM through an intraperitoneal injection. DSS indicates the introduction of 4\% DSS into drinking water and 5-ASA indicates the introduction of $0.15 \%$-ASA to feed. The plain water condition involved the administration of a basal diet and tap water. DSS, dextran sodium sulfate; 5-ASA, 5-aminosalicylic acid; AOM, azoxymethane.

were excised, sliced longitudinally, and rinsed in saline. The length of the colon and the number of tumors present were also determined.

Immunohistochemistry and assessment. A total of 66 biopsy specimens of colorectal tissue obtained from patients with IBD and 30 normal controls were immunohistochemically stained for the expression of PPAR- $\gamma$. Paraffin-embedded $4-\mu \mathrm{m}$ thick sections of the tissues were deparaffinized in $100 \%$ xylene and rehydrated in descending ethanol dilutions, according to standard protocols (16). Heat-induced antigen retrieval was performed in CBS buffer ( $\mathrm{pH} 6.0$ ) for $10 \mathrm{~min}$ at $100^{\circ} \mathrm{C}$. Endogenous peroxidase activity and non-specific antigens were blocked with peroxidase blocking reagent containing $3 \%$ hydrogen peroxide and serum, followed by incubation with rabbit polyclonal antibody against human PPAR- $\gamma$ (dilution, 1:50; Abcam, Cambridge, UK) overnight at $4^{\circ} \mathrm{C}$. Subsequent to washing, the sections were incubated with HRP-labeled secondary antibody for $40 \mathrm{~min}$ at $37^{\circ} \mathrm{C}$. The peroxidase reaction was developed using 3,3'-diaminobenzidine (DAB) chromogen solution in DAB buffer substrate (ChemMate and EnVision Detection kit; Gene Tech (Shanghai) Co., Ltd., Shanghai, China). Sections were visualized using DAB counterstained with hematoxylin, mounted in neutral gum and analyzed using a bright field microscope (Olympus Corporation, Tokyo, Japan).

The stained samples were scored by two independent observers for the proportion of epithelial cells that stained for PPAR- $\gamma$ expression, resulting in scores of 1 for $<25 \%$ of cells being stained, 2 for $25-50 \%$ and 3 for $>50 \%$. The samples were also scored for the intensity of epithelial staining relative to that observed in adjacent endothelial cells, resulting in scores of 0-3 for absent, weak, moderate and strong staining, respectively. The adjacent endothelial cells acted as an internal positive control. PPAR- $\gamma$ expression was quantified subjectively by summating the scores obtained for the intensity and proportion of stained cells, as follows: Absent expression, $0-1$; weakly positive $(+), 2$; moderately positive $(++), 3-4$; and strongly positive $(+++), 5-6$. For statistical analysis, patients with staining between + and +++ were grouped together as the PPAR- $\gamma$-positive group. Associations were assessed between the proportion and intensity of PPAR- $\gamma$ immunoreactivity and the clinical characteristics of the patients.

Reverse transcription quantitative polymerase chain reaction (PCR). Total RNA was extracted from frozen tissues using the TRIzol reagent method. Briefly, $1 \mathrm{ml}$ of TRIzol (Life Technologies, Grand Island, NY, USA) was added to 50-100 $\mathrm{mg}$ of tissue and the tissue was homogenized in an RNase-free environment. Chloroform was then added at a concentration of $200 \mu \mathrm{l}$ chloroform per $1 \mathrm{ml}$ TRIzol, and the samples were centrifuged at $12,000 \mathrm{xg}$ for $15 \mathrm{~min}$ at $4^{\circ} \mathrm{C}$. The aqueous layer was then transferred into a fresh tube and RNA was precipitated with isopropanol followed by one wash using $70 \%$ ethanol. The RNA precipitate was then dissolved into $10-15 \mu \mathrm{l}$ of RNase-free water and analyzed for quantity and quality using a spectrophotometer. A two-step reverse transcription-PCR procedure was performed. Total RNA was reverse transcribed using the GeneAmp kit (Takara Bio, Inc., Otsu, Shiga, Japan). Quantitative PCR was performed on an MJ Opticon 2 real-time PCR system (Opticon, Hoofddorp, Netherlands) according to the manufacturer's instructions. Subsequent to setting the amplification conditions, the experiments were repeated twice. The primers used were as follows: PPAR- $\gamma$ forward, 5'-GCCTCCCTGATGAATAAAGATG-3' and reverse, 5'-AGGCTCCATAAAGTCACCAAAG-3'; GAPDH forward, 5'-GGTGAAGGTCGGTGTGAACG-3' and reverse, 5'-CTCGCTCCTGGAAGATGGTG-3'. The PCR cycling program was changed to $95^{\circ} \mathrm{C}$ for $1 \mathrm{~min}$, and then 40 cycles were performed at $94^{\circ} \mathrm{C}$ for $30 \mathrm{sec}, 60^{\circ} \mathrm{C}$ for $30 \mathrm{sec}$ and $72^{\circ} \mathrm{C}$ for $30 \mathrm{sec}$. Data analysis was performed using the Opticon Monitor 3 software. The results were expressed as fold-change in relative mRNA expression level, calculated using the $2^{-\Delta \Delta C t}$ method, with GAPDH acting as the reference gene and the normal tissue providing a baseline. 

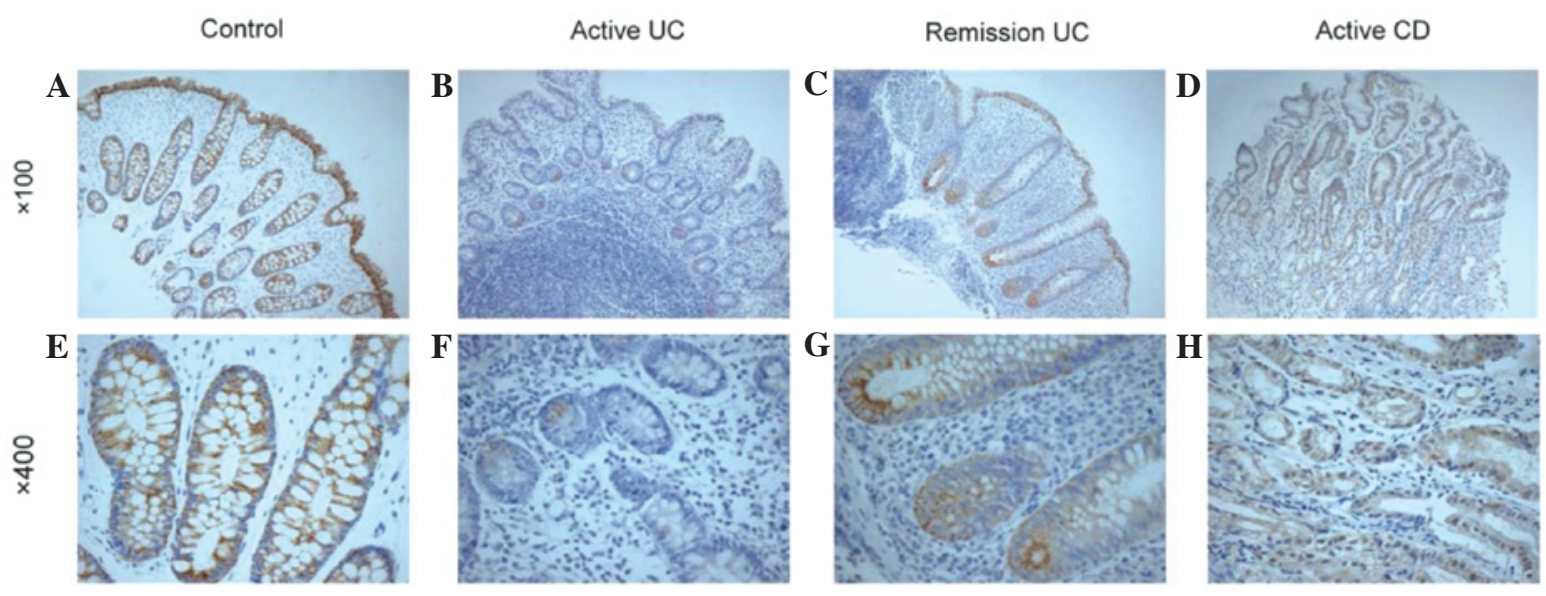

Figure 2. Immunohistochemistry staining for PPAR- $\gamma$ of IBD patients. PPAR- $\gamma$ immunoreactivity was detected in specimens of human colorectal mucosa by immunoperoxidase staining. (A and E) Normal control group showing positive staining in the crypt. (B and F) Ulcerative colitis in active stage showing negative staining in the crypts. (C and G) Ulcerative colitis in remission stage showing patchy PPAR- $\gamma$ immunoreactivity throughout the gland. (D and H) Crohn's colitis in active stage showing strong positive staining toward the crypts. (A-D) magnification, x100; (E-H) magnification, x400.

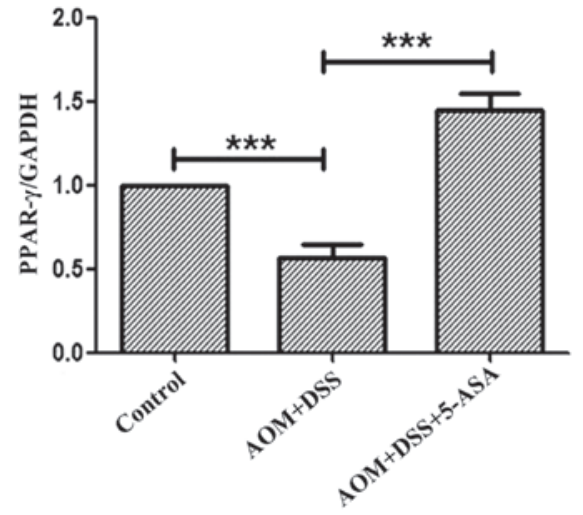

Figure 3. PPAR- $\gamma$ expression is upregulated by 5-ASA in vivo. The expression of the PPAR- $\gamma$ gene was measured by reverse transcription quantitative polymerase chain reaction in the colon samples. ${ }^{* * *} \mathrm{P} \leq 0.001$. PPAR $-\gamma$, peroxisome proliferator-activated receptor- $\gamma$; DSS, dextran sodium sulfate; 5 -ASA, 5-aminosalicylic acid; AOM, azoxymethane.

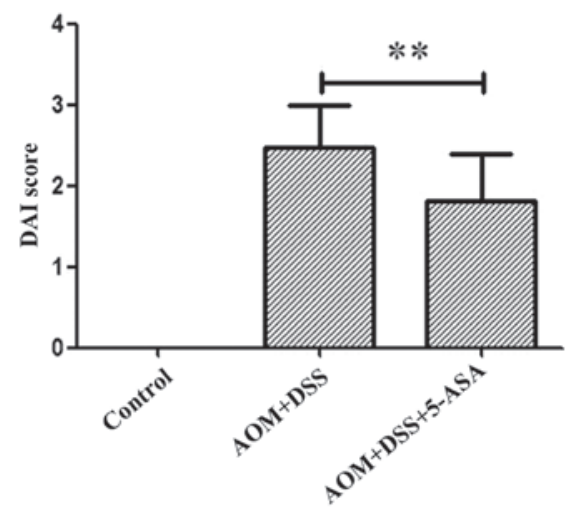

Figure 4. General assessment of colitis based on the DAI. DAI was reduced subsequent to treatment with 5-ASA, compared with the AOM/DSS group. ${ }^{* *} \mathrm{P} \leq 0.01$. DSS, dextran sodium sulfate; 5-ASA, 5-aminosalicylic acid; AOM, azoxymethane; DAI, disease activity index.

Statistical analyses. Data are presented as the mean \pm standard deviation. Statistical analysis was performed using SPSS statistical software, version 13.0, for Windows (SPSS, Inc.,
Chicago, IL, USA). For comparisons between groups, analysis of variance and Student's $t$-test were used. $\mathrm{P}<0.05$ was considered to indicate a statistically significant difference.

\section{Results}

Expression of PPAR- $\gamma$ is attenuated in patients with active $U C$ and in the AOM/DSS mouse model. Immunohistochemical analysis revealed that PPAR- $\gamma$ was expressed in the cytoplasm and nuclei of cells in IBD tissues and normal intestinal epithelium. As shown in Fig. 2 and Table I, compared with healthy control individuals and CD patients, the expression of PPAR- $\gamma$ in the intestinal tissue of patients with UC was significantly decreased $(\mathrm{P}=0.027$ and 0.046 , respectively). The expression of PPAR- $\gamma$ was significantly associated with the activity of UC $(\mathrm{P}=0.028)$. However, PPAR- $\gamma$ expression was not associated with the severity of disease, site of lesions or clinical characteristics of patients with CD (P>0.05; Table II). Downregulation of PPAR- $\gamma$ mRNA in the intestinal tissue of the AOM/DSS model compared with that of the AOM/DSS/5-ASA and control group was also identified (Fig. 3), and this downregulation was statistically significant $(\mathrm{P}<0.001)$.

Colitis-associated colorectal dysplasias are inhibited and the expression of PPAR- $\gamma$ is promoted in the intestinal tract by 5-ASA. Colorectal inflammation was utilized to assess the symptoms associated with colitis, and the DAI was recorded at the end of the first week. The AOM/DSS group demonstrated an increase in the DAI compared with the control group (Fig. 4), and this parameter was clearly reduced in the 5-ASA group $(\mathrm{P}=0.009)$. HE staining revealed neutrophil infiltration of the lamina propria and mucosa and destruction of the intestinal glands in the AOM/DSS group. However, the 5-ASA group demonstrated attenuated inflammation and renewal of the crypts (Fig. 5).

In total, two mortalities occurred when the animals were challenged with DSS in cycles 1 and 3, respectively. Diarrhea and blood in the stool initially appeared 3-4 days subsequent to the initiation of DSS administration in the AOM/DSS 
Table II. Characteristics of the patients with regard to peroxisome proliferator-activated receptor- $\gamma$ expression.

A, Patients with ulcerative colitis $(n=38)$

\begin{tabular}{lrl}
\hline Characteristics & $\mathrm{n}$ & Positive rate, $\mathrm{n}(\%)$ \\
\hline $\begin{array}{l}\text { Activity of disease } \\
\quad \text { Remission }\end{array}$ & 13 & \\
$\quad$ Active & 25 & $5(61.54)$ \\
Severity & & \\
$\quad$ Mild & 9 & $4(44.44)$ \\
Moderate & 13 & $1(7.69)$ \\
$\quad$ Severe & 3 & $0(0.00)$ \\
Lesion site & & $3(27.27)$ \\
$\quad$ Whole colon & 11 & $7(43.75)$ \\
Left colon & 16 & $2(33.33)$ \\
Rectum and sigmoid & 6 & $1(20.00)$ \\
Rectum & 5 & \\
\hline
\end{tabular}

B, Patients with Crohn's disease $(n=28)$

\begin{tabular}{lrr}
\hline Characteristics & $\mathrm{n}$ & Positive rate, $\mathrm{n}(\%)$ \\
\hline $\begin{array}{l}\text { Activity of disease } \\
\text { Remission }\end{array}$ & 8 & $6(75.00)$ \\
$\quad$ Active & 20 & $11(55.00)$ \\
Severity & & \\
Mild & 7 & $4(57.14)$ \\
Moderate & 11 & $6(54.55)$ \\
Severe & 2 & $1(50.00)$ \\
Lesion site & & \\
Intestinal & 16 & $10(62.50)$ \\
Colon & 7 & $5(71.43)$ \\
Ileocolon & 5 & $2(40.00)$ \\
\hline
\end{tabular}

${ }^{\mathrm{a}} \mathrm{P}<0.05 .{ }^{\mathrm{b}}$ Cochran-Armitage trend test, $\mathrm{P}=0.031$.

group, and ceased at 7-9 days after the removal of DSS from the water supply, during which the mice exhibited messy body hair, malaise and a lack of exercise. The average appearance of diarrhea and bloody stools in the 5-ASA treatment group commenced 1-2 days subsequent to the initial administration of DSS, with mild symptoms and a faster recovery. Three mice were observed to have developed perianal tumors in the AOM/DSS group, one of which comprised ulcers and bleeding. During the observation period, the AOM/DSS and 5-ASA groups each demonstrated an inconsistent weight loss and recovery curve (Fig. 6A). The difference between the body weight of mice in the two groups in week 9 was statistically significant ( $\mathrm{P}=0.002$; Table III).

In visual observation, the AOM/DSS group possessed intestinal edema, intestinal deformation, brittle intestines and bled easily. The administration of 5-ASA significantly prevented the shortening of the colorectum in the treatment group $(\mathrm{P}=0.01)$, and the average number of tumors in the group administered with 5-ASA was significantly reduced $(\mathrm{P}<0.001)$, which demonstrated the protective properties of 5-ASA (Fig. 6B and C; Table III). Flat dysplasia and dysplasia-associated lesions or masses were each revealed in the AOM/DSS group by HE staining, with the presence of a high degree of atypical hyperplasia and carcinoma in situ. However, atypical hyperplasia was more common in the group treated with 5-ASA (data not shown).

PPAR- $\gamma$ was considered to play a role in 5-ASA-mediated protection against AOM/DSS-induced colitis-associated neoplasia. Colon homogenates from the treatment group revealed that 5-ASA increased the transcriptional expression of PPAR- $\gamma(\mathrm{P}<0.001$; Fig. 3).

\section{Discussion}

PPAR $-\gamma$ is a ligand-activated transcription factor that was originally identified as a receptor expressed in adipose tissue, where it played a role in adipocyte differentiation and in the regulation of insulin responses. The human PPAR- $\gamma$ gene is located on chromosome $3 \mathrm{p} 25$, and three mRNA transcript variants that encode two isoforms of PPAR- $\gamma$, PPAR- $\gamma 1$ and PPAR- $\gamma 2$, have been found. The colon has been identified as one of the tissues expressing the highest levels of PPAR- $\gamma$, next to adipose tissue in epithelial cells and, to a lesser degree, macrophages and lymphocytes $(17,18)$. In the cellular system, PPAR exists as a heterodimer formed with retinoid $\mathrm{X}$ receptor (RXR). Upon activation by endogenous or synthetic ligands, PPAR binds to specific PPAR response elements (PPREs) in the target genes and acts as a transcriptional regulator (19). In addition, PPAR- $\gamma$ is also able to interfere with other transcriptional factors through a non-DNA binding mode. This interference is mediated by physical association between the heterodimer of PPAR and RXR and other activated transcription factors, such as Janus kinase/signal transducer and activator of transcription (20), nuclear factor- $\kappa \mathrm{B}(21)$ and nuclear factor of activated T-cells (22), thereby blocking the functions of the factors. In addition, excessive binding of the shared co-activators with the PPAR-RXR dimer renders these co-activators unavailable for other transcription factors and therefore prevents the activation of the transcription factors (23). Macrophage-specific PPAR $-\gamma$ deletion significantly impaired the splenic and mesenteric lymph node regulatory $\mathrm{T}$ cell component. In addition, macrophage-specific PPAR- $\gamma$ deletion increased the proportion of lamina propria $\mathrm{CD}^{+} \mathrm{T}$ cells expressing $\mathrm{CD} 40$, Ly6C and TLR-4 on the cell surface. The expression of colonic IFN- $\gamma$, CXCL9, CXCL10, IL-22, IL1RL1, CCR1, suppressor of cytokine signaling 3 and MHC class II was also upregulated in mice with IBD (24).

In the present study, it was found that PPAR- $\gamma$ was downregulated in active UC and the expression of PPAR- $\gamma$ was significantly associated with disease activity. These findings demonstrated that deregulation of PPAR $-\gamma$ may play an important role in the pathogenic process of UC. The present data were also consistent with the results obtained by Yamamoto-Furusho et al (25), which indicated that the mRNA expression of PPAR $-\gamma$ was decreased in rectal mucosa from patients with active UC compared with UC patients in remission, and PPAR- $\gamma$ gene expression was negatively correlated with endoscopic activity, as determined by Spearman 
Table III. General observations and gross anatomy of the mice in the treatment and control groups.

\begin{tabular}{lcccc}
\hline Group & Survival rate, $\mathrm{n}(\%)$ & Body weight, $\mathrm{g}$ & Length of colon, cm & Tumor number \\
\hline Control & $9(100.0)$ & $23.31 \pm 0.47$ & $8.59 \pm 0.63$ & 0 \\
AOM+DSS & $7(77.8)$ & $19.90 \pm 1.37$ & $7.26 \pm 0.60$ & $9.71 \pm 2.29$ \\
5-ASA treatment & $9(100.0)$ & $21.80 \pm 0.56^{\mathrm{b}}$ & $8.22 \pm 0.67^{\mathrm{a}}$ & $4.11 \pm 1.05^{\mathrm{b}}$ \\
\hline
\end{tabular}

Data are presented as the mean \pm standard deviation. ${ }^{a} \mathrm{P}<0.05$ vs. AOM/DSS group. ${ }^{\mathrm{b}} \mathrm{P}<0.01 \mathrm{vs}$. AOM/DSS group. DSS, dextran sodium sulfate; AOM, azoxymethane; 5-ASA, 5-aminosalicylic acid.

A

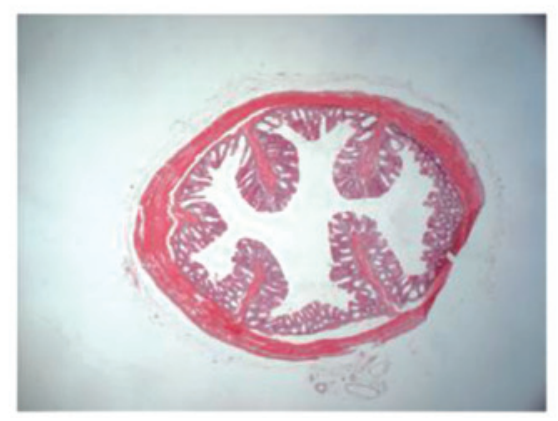

B

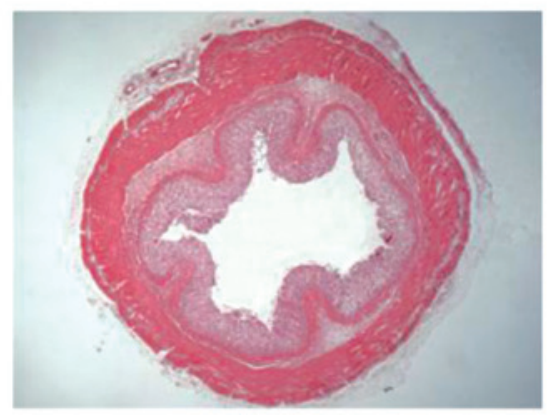

C AOM+DSS+5-ASA

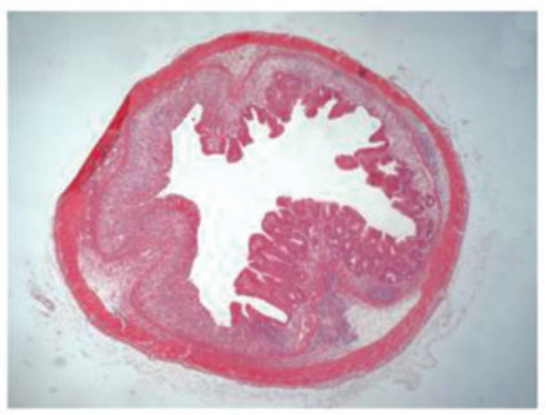

Figure 5. Representative colon glands in each group. (A) Normal control demonstrating dendritic colon villi. (B) AOM/DSS group exhibiting eroded glands and congregated leukocytes. (C) Erosion and inflammation was alleviated by 5-ASA. DSS, dextran sodium sulfate; 5-ASA, 5-aminosalicylic acid; AOM, azoxymethane.

A

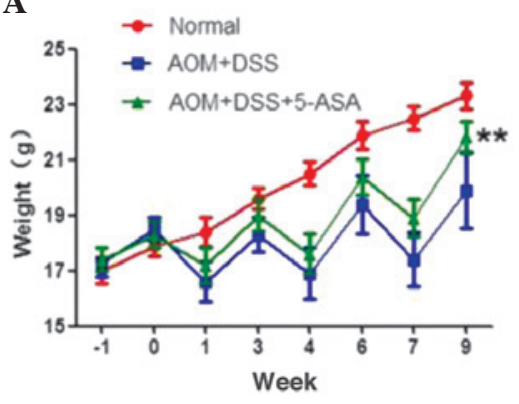

B

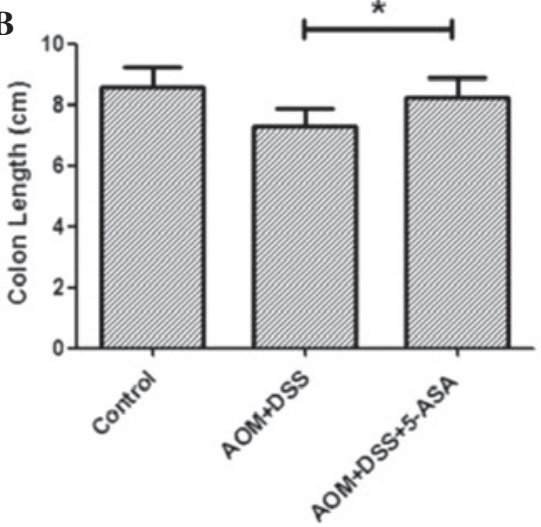

C

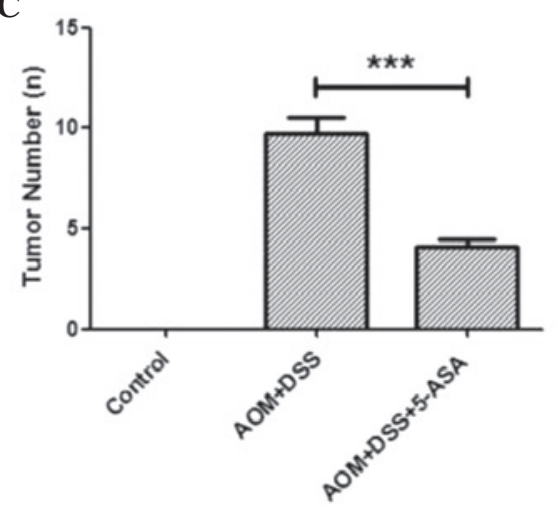

Figure 6. Changes in body weight and gross anatomy. (A) Changes in body weight. The difference between the body weight of mice in the AOM/DSS group and those in the 5-ASA group was statistically significant in week 9. (B and C) Colon length and tumor number measurements after 3 cycles of DSS. "P $\leq 0.05$, ${ }^{* *} \mathrm{P} \leq 0.01$ and ${ }^{* * *} \mathrm{P} \leq 0.001$. DSS, dextran sodium sulfate; 5-ASA, 5-aminosalicylic acid; AOM, azoxymethane; W, week.

correlation test. The present study did not identify a correlation between the expression of PPAR- $\gamma$ and the site of UC lesions, which indicates that PPAR- $\gamma$ was involved in an alternative component of the UC intestinal inflammation.

UC is associated with an increased risk of colorectal cancer. It is estimated that only $20-50 \%$ of colonic neoplasms are detected during routine colonoscopy (26). The chemopreventive effect of 5-ASA is therefore of considerable interest, and several studies $(27,28)$ have examined the ability of 5-ASA to inhibit colorectal cancer in murine models, but the mechanism of the anti-neoplastic effects of 5-ASA remain ambiguous. The pathogenesis of CAC is widely considered to involve a step-wise progression from inflamed and hyperplastic epithelia to flat dysplasia and finally to adenocarcinoma (29). CAC is probably promoted by chronic inflammation, although the mechanism remains unclear. In the present study, preventive oral administration of 5-ASA attenuated acute colitis as observed by a significant reduction of the disease activity index (DAI), histological/microscopic damage score in colonic tissue. The anti-neoplastic effect may be partly attributable to the inhibition of inflammation.

However, previous studies have reported that the antineoplastic effects of 5-ASA did not completely rely on the anti-inflammation effect. Clapper et al (30) reported that an inverse association was observed between the dose of 5-ASA administered and the multiplicity of colonic dysplasias. 
Inflammation was least severe in the group administered with $75 \mathrm{mg} / \mathrm{kg}$ 5-ASA, which exhibited the fewest number of colorectal tumors. This contradictory result suggested that 5-ASA may utilize an alternative mechanism for suppressing carcinoma. Rousseaux et al (7) reported that 5-ASA exerted its effects in the colon through direct PPAR activation, as it was of interest to elucidate the dependence of the 5-ASA anti-proliferative effects on PPAR- $\gamma$. Due to the association between decreased PPAR- $\gamma$ expression and colonic carcinoma and inflammation in the present study, it was hypothesized that the chemopreventive effects of 5-ASA appear to be mediated, at least in part, by PPAR- $\gamma$ activation.

The wnt/ $\beta$-catenin-TCF signaling pathway has been reported to play a critical role in the process of colorectal cancer (31). $\beta$-catenin is an important element of the wnt/ $\beta$-catenin-TCF signaling pathway and is also a key regulator of the cadherin-mediated cell-cell adhesion system. The increased expression of $\beta$-catenin that results from mutation of the APC gene has been considered as the primary mediator of colon carcinogenesis (23). In sporadic colon cancer, PPAR- $\gamma$ was found to interfere with transcription in the wnt signaling pathway through competition with $\beta$-catenin for co-activating factors; mutations of the tumor suppressor gene APC that result in APC inhibition and activation of glycogen synthase kinase $3 \beta$ (32) accelerated the phosphorylation of $\beta$-catenin. A previous study demonstrated that 5-ASA treatment did not alter the expression of $\beta$-catenin (28). These data suggest that the protective effect exerted by PPAR- $\gamma$ may not involve the wnt/ $\beta$-catenin-TCF signaling pathway. The etiology underlying impaired PPAR- $\gamma$ expression in colonic epithelial cells in UC and CAC has yet to be elucidated. One common polymorphism in the PPAR- $\gamma$ gene is a proline to alanine substitution (Pro12Ala) that results in a missense substitution from CCA to GCA in codon 12 of exon 2 of the PPAR- $\gamma$ gene. Previous studies $(33,34)$ have aimed to explore the association between the Pro12Ala polymorphism in the PPAR- $\gamma$ gene and UC disease activity. The results indicated that the frequency of Pro/Alo heterozygotes for the PPAR- $\gamma$ gene was not significantly different between the UC and control groups, which suggested that the dysfunction of PPAR- $\gamma$ may not be regulated at the gene level, but at the post-transcription level. Previous studies have found that during the process of LPS-stimulated downregulation of PPAR- $\gamma$, the half-life of the PPAR- $\gamma$ mRNA was shortened, and small non-coding RNA, termed microRNA, may be involved in this process (35). To clarify the downregulation mechanism of PPAR- $\gamma$ under inflammatory status may become the focus of further study.

In conclusion, the present study demonstrated that PPAR- $\gamma$ plays an important role in the pathogenic process of UC and CAC. Based on the present findings, the chemopreventive effect was considered to possibly be explained in part by the upregulation of PPAR $-\gamma$. Therefore, targeting PPAR $-\gamma$ may provide a novel and promising approach for the treatment of $\mathrm{UC}$ and the prevention of CAC.

\section{Acknowledgements}

The authors would like to thank Yueqin Tang and Chengmin Qiu for their technical assistance.

\section{References}

1. Munkholm P: Review article: The incidence and prevalence of colorectal cancer in inflammatory bowel disease. Aliment Pharmacol Ther 18 (Suppl 2): 1-5, 2003.

2. Cheng Y and Desreumaux P: 5-aminosalicylic acid is an attractive candidate agent for chemoprevention of colon cancer in patients with inflammatory bowel disease. World J Gastroenterol 11: 309-314, 2005.

3. Debril MB, Renaud JP, Fajas L and Auwerx J: The pleiotropic functions of peroxisome proliferator-activated receptor gamma. J Mol Med Berl 79: 30-47, 2001.

4. Hontecillas R and Bassaganya-Riera J: Peroxisome proliferator-activated receptor gamma is required for regulatory CD4+ T cell-mediated protection against colitis. J Immunol 178: 2940-2949, 2007.

5. Schwab M, Reynders V, Loitsch S, Shastri YM, Steinhilber D, Schröder O and Stein J: PPARgamma is involved in mesalazine-mediated induction of apoptosis and inhibition of cell growth in colon cancer cells. Carcinogenesis 29: 1407-1414, 2008.

6. van Staa TP, Card T, Logan RF and Leufkens HG: 5-Aminosalicylate use and colorectal cancer risk in inflammatory bowel disease: A large epidemiological study. Gut 54: 1573-1578, 2005.

7. Rousseaux C, Lefebvre B, Dubuquoy L, Lefebvre P, Romano O, Auwerx J, Metzger D, Wahli W, Desvergne B, Naccari GC, et al: Intestinal antiinflammatory effect of 5-aminosalicylic acid is dependent on peroxisome proliferator-activated receptor-gamma. J Exp Med 201: 1205-1215, 2005.

8. Koelink PJ, Mieremet-Ooms MA, Corver WE, Wolanin K, Hommes DW, Lamers CB and Verspaget HW: 5-aminosalicylic acid interferes in the cell cycle of colorectal cancer cells and induces cell death modes. Inflamm Bowel Dis 16: 379-389, 2010.

9. Kohno H, Suzuki R, Sugie S and Tanaka T: Suppression of colitis-related mouse colon carcinogenesis by a COX-2 inhibitor and PPAR ligands. BMC Cancer 5: 46, 2005.

10. Cooper HS, Murthy SN, Shah RS and Sedergran DJ: Clinicopathologic study of dextran sulfate sodium experimental murine colitis. Lab Invest 69: 238-249, 1993.

11. Ni J, Chen SF and Hollander D: Effects of dextran sulphate sodium on intestinal epithelial cells and intestinal lymphocytes. Gut 39: 234-241, 1996.

12. Cooper HS, Everley L, Chang WC, Pfeiffer G, Lee B, Murthy S and Clapper ML: The role of mutant Apc in the development of dysplasia and cancer in the mouse model of dextran sulfate sodium-induced colitis. Gastroenterology 121: 1407-1416, 2001.

13. Tanaka T, Kohno H, Suzuki R, Hata K, Sugie S, Niho N, Sakano K, Takahashi $M$ and Wakabayashi K: Dextran sodium sulfate strongly promotes colorectal carcinogenesis in Apc(Min/+) mice: Inflammatory stimuli by dextran sodium sulfate results in development of multiple colonic neoplasms. Int J Cancer 118: 25-34, 2006.

14. Murano M, Maemura K, Hirata I, Toshina K, Nishikawa T, Hamamoto N, Sasaki S, Saitoh O and Katsu K: Therapeutic effect of intracolonically administered nuclear factor kappa B (p65) antisense oligonucleotide on mouse dextran sulphate sodium (DSS)-induced colitis. Clin Exp Immunol 120: 51-58, 2000.

15. Onderdonk AB and Bartlett JG: Bacteriological studies of experimental ulcerative colitis. Am J Clin Nutr 32: 258-265, 1979.

16. Jin Z, Jiang W, Jiao F, Hu H, Guo Z, Wang L and Wang L: Decreased expression of histone deacetylase 10 predicts poor prognosis of gastric cancer patients, Int J Clin Exp Pathol 7: 5872-5879, 2014.

17. Dubuquoy L, Dharancy S, Nutten S, Pettersson S, Auwerx J and Desreumaux P: Role of peroxisome proliferator-activated receptor gamma and retinoid X receptor heterodimer in hepatogastroenterological diseases. Lancet 360: 1410-1418, 2002.

18. Dubuquoy L, Rousseaux C, Thuru X, Peyrin-Biroulet L, Romano O, Chavatte P, Chamaillard M and Desreumaux P: PPARgamma as a new therapeutic target in inflammatory bowel diseases. Gut 55: 1341-1349, 2006.

19. Grommes C, Landreth GE and Heneka MT: Antineoplastic effects of peroxisome proliferator-activated receptor gamma agonists. Lancet Oncol 5: 419-429, 2004.

20. Chen CW, Chang YH, Tsi CJ and Lin WW: Inhibition of IFN-gamma-mediated inducible nitric oxide synthase induction by the peroxisome proliferator-activated receptor gamma agonist, 15-deoxy-delta 12,14-prostaglandin J2, involves inhibition of the upstream Janus kinase/STAT1 signaling pathway. J Immunol 171: 979-988, 2003. 
21. Sánchez-Hidalgo M, Martín AR, Villegas I and Alarcón De La Lastra C: Rosiglitazone, an agonist of peroxisome proliferator-activated receptor gamma, reduces chronic colonic inflammation in rats. Biochem Pharmacol 69: 1733-1744, 2005.

22. Yang XY, Wang LH, Chen T, Hodge DR, Resau JH, DaSilva L and Farrar WL: Activation of human T lymphocytes is inhibited by peroxisome proliferator-activated receptor gamma (PPARgamma) agonists. PPARgamma co-association with transcription factor NFAT. J Biol Chem 275: 4541-4544, 2000.

23. Krishnan A, Nair SA and Pillai MR: Biology of PPAR gamma in cancer: A critical review on existing lacunae. Curr Mol Med 7: 532-540, 2007.

24. Hontecillas R, Horne WT, Climent M, Guri AJ, Evans C, Zhang Y, Sobral BW and Bassaganya-Riera J: Immunoregulatory mechanisms of macrophage PPAR- $\gamma$ in mice with experimental inflammatory bowel disease. Mucosal Immunol 4: 304-313, 2011.

25. Yamamoto-Furusho JK, Peñaloza-Coronel A, Sánchez-Muñoz F, Barreto-Zuñiga R and Dominguez-Lopez A: Peroxisome proliferator-activated receptor-gamma (PPAR- $\gamma$ ) expression is downregulated in patients with active ulcerative colitis. Inflamm Bowel Dis 17: 680-681, 2011.

26. Farrell RJ and Peppercorn MA: Ulcerative colitis. Lancet 359: 331-340, 2002.

27. Ikeda I, Tomimoto A, Wada K, Fujisawa T, Fujita K, Yonemitsu K, Nozaki Y, Endo H, Takahashi H, Yoneda M, et al: 5-aminosalicylic acid given in the remission stage of colitis suppresses colitis-associated cancer in a mouse colitis model. Clin Cancer Res 13: 6527-6531, 2007.

28. Koelink PJ, Robanus-Maandag EC, Devilee P, Hommes DW, Lamers CB and Verspaget HW: 5-Aminosalicylic acid inhibits colitis-associated but not sporadic colorectal neoplasia in a novel conditional Apc mouse model. Carcinogenesis 30: 1217-1224, 2009.
29. Riddell RH, Goldman H, Ransohoff DF, Appelman HD, Fenoglio CM, Haggitt RC, Ahren C, Correa P, Hamilton SR, Morson BC, et al: Dysplasia in inflammatory bowel disease: Standardized classification with provisional clinical applications. Hum Pathol 14: 931-968, 1983.

30. Clapper ML, Gary MA, Coudry RA, Litwin S, Chang WC, Devarajan K, Lubet RA and Cooper HS: 5-aminosalicylic acid inhibits colitis-associated colorectal dysplasias in the mouse model of azoxymethane/dextran sulfate sodium-induced colitis. Inflamm Bowel Dis 14: 1341-1347, 2008.

31. Saif MW and Chu E: Biology of colorectal cancer. Cancer J 16: 196-201, 2010.

32. Liu J and Farmer SR: Regulating the balance between peroxisome proliferator-activated receptor gamma and beta-catenin signaling during adipogenesis. A glycogen synthase kinase 3beta phosphorylation-defective mutant of beta-catenin inhibits expression of a subset of adipogenic genes. J Biol Chem 279: 45020-45027, 2004

33. Atug O, Tahan V, Eren F, Tiftikci A, Imeryuz N, Hamzaoglu $\mathrm{HO}$ and Tozun N: Pro12Ala polymorphism in the peroxisome proliferator-activated receptor-gamma (PPARgamma) gene in inflammatory bowel disease. J Gastrointestin Liver Dis 17: 433-437, 2008

34. Shrestha UK, Karimi O, Crusius JB, Zhou F, Wang Z, Chen Z, van Bodegraven AA, Xiao J, Morré SA, Wang H, et al: Distribution of peroxisome proliferator-activated receptor-gamma polymorphisms in Chinese and Dutch patients with inflammatory bowel disease. Inflamm Bowel Dis 16: 312-319, 2010.

35. Jennewein C, von Knethen A, Schmid T and Brüne B: MicroRNA-27b contributes to lipopolysaccharide-mediated peroxisome proliferator-activated receptorgamma(PPARgamma) mRNA destabilization. J Biol Chem285: 11846-11853, 2010. 